Int. J. Electrochem. Sci., 15 (2020) 4056 - 4064

\title{
Photoelectrochemical and Optical Properties of ZnO Nanorods Grown on ITO/polyethersulphone Polymer Substrates Using Aqueous Solution Method: The Effect of Precursor Concentration
}

\section{Yuqin Jing}

School of Electronic Information Engineering, Chong Qing Technology and Business Institute, Chongqing 401520, China

E-mail: yuqinjing_cq@163.com

doi: $10.20964 / 2020.05 .59$

Received: 12 November 2019 / Accepted: 7 February 2020 / Published: 10 April 2020

Well-aligned $\mathrm{ZnO}$ nanostructures were successfully grown on indium tin oxide (ITO)/ polyethersulphone (PES) polymer substrates using aqueous solution method to study the precursor concentration effect on photoelectrochemical and optical properties of prepared samples. Field-emission scanning electron microscopy (FESEM) was used to characterize the surface morphology of the samples. Photoelectrochemical and optical properties of $\mathrm{ZnO}$ nanorods were done by $\mathrm{UV}$-vis spectrophotometer, photoluminescence (PL) and solar simulator tests. The FESEM images demonstrated that smaller diameter and higher-density distribution of $\mathrm{ZnO}$ nanorods were observed in the sample with $0.06 \mathrm{M}$ precursor concentration. The optical absorption revealed that the sample with $0.06 \mathrm{M}$ precursor content indicated strangely improved absorption compared to the other samples which can be ascribed to the aspect ratio of the $\mathrm{ZnO}$ nanostructures. The PL measurements of the samples demonstrated a strong and sharp enhancement in UV emission peak at a low concentration $(0.06 \mathrm{M})$ of precursor. Photoelectrochemical performance revealed that a proper amount of precursor significantly improve the conversion efficiency and short current density values compared to that of high amount of precursor which can be attributed to the sufficient light harvesting, more dye absorption and fast charge transfer of the sample.

Keywords: $\mathrm{ZnO}$ nanorods; Polyethersulphone polymer substrate; Aqueous solution method; Photoelectrochemical and optical properties; Precursor concentration

\section{FULL TEXT}


(C) 2020 The Authors. Published by ESG (www.electrochemsci.org). This article is an open access article distributed under the terms and conditions of the Creative Commons Attribution license (http://creativecommons.org/licenses/by/4.0/). 